\title{
LA IMPLANTACION DE LOS CORREGIDORES EN EL CONCEJO MURCIANO (1394-1402)
}

Por

M.` DE LOS LLANOS MARTINEZ CARRILLO 
Fue en los finales del siglo XIV cuando el oficio de corregidor empezó. lenta y trabajosamente, a generalizarse en toda Castilla coincidiendo con las revueltas sociales que se desencadenaron en muchas ciudades y villas del reino, después de que hubiese transcurrido medio siglo desde que Alfonso XI llevó a cabo los primeros intentos de introducción de un oficial real destinado a controlar los municipios: agentes regios los llama Bermúdez para aquella época dada su indefinición y la diversidad de sus cometidos (1). Pero fue efectivamente durante el reinado de Enrique III cuando la institución se concretó en el ámbito castellano, y cuando Murcia protagonizó el conflicto que dio pie en 1394 al nombramiento por primera vez de un corregidor, Ruy Méndez de Sotomayor, un cordobés de origen gallego probablemente, que había representado a su ciudad en 1393 en el consejo de regencia del monarca, y allí, en la corte, debió encontrar las relaciones de poder que le permitieron inspirar confianza a

(1) Benmudez Aznar. A.: El corregidor en Castilla durante la Baja Edad Me. dia (1348-1474). pág. 54. Departamento de Historia del Derecho. Unv. de Murcia. 1974. En las luchas bajomedievales que pusieron fin a lo que Barel llama sistema urbano europeo, cada uno de los grupos acaba combatiendo contra dos enemigos. los internos al sistema y los externos que buscan la territorialización de sus intereses, entre ellos estaba el poder real, de tal modo que tendian a convertirse en árbitros de la situación, Barel. Yves: La ciudad medieval. Sistema social-Sistema urbano. Instituto de Estudios de Administración Local. Madrid 1981. 
los regentes de Enrique III hasta convertirlo en el peón necesario que intentase resolver el enfrentamiento de bandos que en Murcia protagonizaban los Fajardo y los Manuel desde 1391. La institución que con él inició su andadura de forma tambaleante, se convirtió en Murcia y en las demás ciudades del reino, en el principal soporte del poder real a nivel local, durante los siglos sucesivos.

Tan tempestuoso fue su intento de penetración en la ciudad y tan discutidas, por inadmisibles, resultaban lo mismo su presencia que el oficio que venía a servir, que los dos autores clásicos de Historia de Murcia, Cascales y Frutos Baeza (2), considerados tradicionalmente como el punto de referencia de un público no siempre especialista, no lo citan, porque en 1394, año de su venida hasta Molina Seca, no consiguió penetrar en la ciudad e imponer la ley y el orden del rey a los dos bandos enfrentados, que continuaron en una oposición cacla vez más violenta.

No se trata de reducir la Historia a anécdota en estos tiempos, sino de contribuir a explicar a través de unos hechos locales, que tuvieron varias fases en su evolución, la gravedad del proceso social y su degradación en la época en la que la institución y el oficio del corregimiento tuvieron su definitivo origen.
A) Territorialización de los bandos y primeros intentos de pacificación.

Alfonso Yáñez Fajardo, miembro de un linaje nuevo historiado paso a paso por Torres Fontes (3), cuyos orígenes murcianos alcanzan por lo menos los comienzos del siglo XIV, había iniciado un proceso de consolidación en el reino que resultó paralelo a la instauración de la dinastía

(2) Cascales, Francisco: Discursos históricos de Murcia y su Reyno. Imprenta de Francisco Benedito, Murcia 1775. Frutos Baeza, José: Bosquejo histórico de Murcia y su Concejo, "La Verdad", Murcia 1934.

(3) Torres Fontes, Juan: Los Fajardo en los siglos XIV y XV. Miscelánea Medieval Murciana, vol. IV. Departamento de Historia Medieval. Universidad de Murcia 1978. 
Trastámara en Castilla y del que resultaron desplazados Juan Sánchez Manuel, conde de Carrión, y sus descendientes; sustituto del conde en el adelantamiento de Murcia en 1383 consolidó su poder con la adquisición de tres enclaves territoriales, a partir de los cuales resistió el intento recuperador de los Manuel que pasaron a controlar la ciudad de Murcia poco después de la muerte de Juan II en 1390; aquellas tres bases fueron Librilla, Alhama y Molina Seca, adquiridas por donación real respectivamente en 1381, 1387 y 1397, la última un año después de su fallecimiento.

Detrás de estas bases, desempeñando una función de bastión defensivo hacia el interior, Mula, controlada por los Fajardo desde la primera mitad del siglo XIV, actuó en las luchas civiles como un auténtico refugio de sus seguidores, ayudada a menudo por el concejo de Lorca.

Frente a las bases fajardistas, los seguidores de Juan Sánchez Manuel dispusieron del territorio de la huerta, controlado desde la propia Murcia, hasta la frontera aragonesa, con un importante respaldo en Orihuela, tierra de origen de Ramón de Rocafull que era uno de sus principales hombres. Por otro lado las propiedades manuelistas en Santomera, el hecho de que el señorio de Abanilla estuviese en manos próximas a los Rocafull, su titular Juan Fernández de Avellaneda estaba casado con Leonor de Rocafull, y la circunstancia de que Fortuna fuese una aldea dependiente de Murcia, permiten suponer que Monteagudo y su castillo fueron uno de sus objetivos estratégicos permanentes, aunque en este punto no alcanzaron nunca una plena seguridad (4).

(4) E $\vec{n} 1394$ el castillo de Monteagudo. por lo menos, podia ser utilizado contra los intereses de los Manuel con plena eficacia, el 3 de noviembre, a los pocos dias de que el concejo hubiese dado a los murcianos plenas seguridades para que labrasen las tierras en la huerta, el vecino Esteban Martín $y$ su hijo fueron atacados mientras trabajaban las suyas, por peones que salieron del castillo, hirieron grave. mente al hijo, les robaron una yegua $y$ se refugiaron con hombre $y$ bestia en el castillo, obligando al labrador a entregarles a cambio del hijo la otra yegua que tenía; si bien no se puede asegurar plenamente que los asaltantes fueran directamente fajardistas, si queda claro que Monteagudo era utilizado para hostigar los murcianos, en esos momentos gobernados por un concejo manuelista. Acts. Cap. 1394, fol. 07 rev. (4-11-1394). 
En el valle del Segura un cordón de pequeños núcleos de población sometidos a distintas jurisdicciones señoriales se comportaron como "neutrales" en este duro enfrentamiento, siendo el más importante de todos ellos, el señorío episcopal de Alcantarilla, por la doble razón de su proximidad a la ciudad y de ser el vértice de las comunicaciones divergentes entre Murcia, Castilla y Granada; neutralidad no conseguida por el convencimiento o la superación del problema, sino porque la dependencia jurisdiccional respecto a la orden de Santiago, descle Ricote hacia el interior de la cuenca del Segura, cuyos comendadores estaban ligados a los Fajardo o pertenecían a la familia, o a la iglesia como el ya citado de Alcantarilla, cuyo obispo militaba con los Manuel, entre otras jurisdicciones, les obligaba a la neutralización. Hasta Molina-Seca puede decirse que cl valle y su camino hacia Castilla quedaron expeditos a las correrías de unos y otros, mientras que descle este punto hasta la capital, los ataques fajardistas a Murcia eludían el camino tradicional del valle por Alcantarilla, utilizando en cambio uno más recto "campo a través", más parecido a la actual carretera general, en función del cual el castillo de Monteagudo se revalorizaba.

Hasta llegar a conseguir estas bases que pueden considerarse como las existentes en los momentos del desenlace, el enfrentamiento de Alfonso Yáñez Fajardo y Juan Sánchez Manuel fue agravándose progresivamente a partir de 1391 y acabó concretándose en la expulsión definitiva de la ciudad del primero y sus más aclictos defensores en 1393, mientras que Murcia se convertía en un bastión donde Juan Sánchez Manuel y los suyos imponían su ley, negándose a cualquier intento de concordia que pasase por la readmisión de los expulsados. Este fue el problema de desobediencia en un contexto de duras dificultades económicas que los regentes de Enrique III trataron de resolver en 1394 enviando un corregidor a la ciudad.

Este corregidor fue Ruy Méndez de Sotomayor, que en febrero de aquel año llegaba a las tierras surestinas y se instalaba en Molina Seca 





ante la real imposibilidad que encontró de penetrar en Murcia, por la resistencia armada que el concejo le presentó. La villa quedó de este modo convertida en el punto más próximo a Murcia hasta donde la autoridad real ordenando la readmisión de los Fajardo en ella podía llegar, y probablemente fue este hecho político el que revalorizó la importancia estratégica de este pequeño núcleo de población que era el primero en el camino hacia el interior de Castilla, una vez traspasados los límites naturales de la huerta del Segura. Quién sabe si no fue ello, la causa próxima de la concesión de su señorío en 1397 al primogénito de Alfonso Yáñez Fajardo, Juan Alfonso Fajardo.

Desde Molina Seca, Sotomayor hizo llegar al concejo murciano y a sus dirigentes y árbitros los Manuel, las dos cartas reales que teóricamente lo capacitaban para entrar en ella y ejercer sus funciones, una de creencica y otra de seguro, con las cuales debía ser creído y obedecido como corregidor, a más de respetado en su persona y en sus bienes al igual que sus hombres: “...que el dicho Ruy Mendes e todos los que con el fueren o binieren a esa dicha çibdat, vayan e vengan e estén en ella saluos y seguros e sin reçelo alguno por vos otros o por algunos de vos, nin por los que por vos an de faser al dicho Ruy Mendes nin a los omnes que con él fueren..." (5).

Según ésto, la llegada de Sotomayor tenía como objetivo poner paz entre los bandos ciudadanos en contienda, una vez que los Fajardo hubieran sido admitidos de nuevo en la ciudad, y evitar que en el futuro se repitiesen hechos semejantes, “...porque todos ayades pas et amorio e bivades en sosiego..." (6).

Pero el problema empezaba a estar lo suficientemente enconado como para que estos objetivos no se cumplieran tan fácilmente; los líderes murcianos presentes en el concejo general que se celebró en la plaza de Santa

(5) Illescas 22-1-1394, Acts. Cap. 1393-1394 fol. 157 rev. (10-2-1394).

(6) Acts. Cap. 1393-94, fol 192 (5-4-1394) 
María del Alcázar se encargaron de impedirlo: Andrés García de Laza y don Ramón de Rocafull, que eran los dos personajes a quienes se dirigía la orden real, interrogaron a los vecinos que se habian reunido en la plaza sobre si convenía o no dejar pasar al corregidor, y con el radicalismo propio de un proceso revolucionario dirigido por miembros de la oligarquía, pero con raíces socioeconómicas en las bases urbanas, contestaron que el asunto no estaba en sus manos, “...salvo en mano del pueblo.", porque el concejo general habia ordenado no acoger a ninguna "persona poderosa", hasta que Fajardo soltase a los vecinos de Murcia que a su vez tenía presos.

B) Radicalización concejil e imposición de los oficiales reales.

A partir de entonces no hubo ya ningúm acuerdo conducente a la admisión clel corregidor Ruy Méndez de Sotomayor, y mucho menos al pago de 3.000 maravedis en concepto de costas del viaje realizado hasta Murcia tal como ordenaba otro albalí real (7), que preveía que ante la posibilidad nada remota, de que la ciudad tuviese dificultades económicas para concretarlos y se viese en la necesidad de recurrir al préstamo o a la incautación de arrendadores, como solía ser usual, el tesorero mayor de Andalucía, Juan Fernández de Villafranca, los admitiría en cuenta con la presentación del albalá y una carta de pago del propio Ruy Méndez. Pero nada de ello fue necesario porque el concejo dio la callada y la cerrazón de sus puertas por toda respuesta.

Desde aquel momento la radicalización se acentuó y los emisarios, venidos unas veces y anunciados otras, desde la corte, no solucionaron nada; los concejos abiertos celebrados en cadena fueron el único órgano de gobjerno de Murcia durante estos años, “...que por aclamación aprueban $y$ ratifican fielmente los dictados de Garcia de Laza..." (8), el in-

(7 Act. Cap. 1393-94, fol. 172 (21-3-1394).

(8) Torres Fontes, J.: Relación mutciana de los López de Ayala en los siglos XIII y XIV, pág. 28. Academia Alfonso X el Sabio, Murcia. 1976. 
dividuo que dirigió la revuelta, desde que en 1395 Juan Sánchez Manuel, viendo el asunto perdido, se refugió en Orihuela, y hasta su ejecución en 1399 por obra del adelantado mayor y condestable de Castilla Ruy López de Dávalos, de cuya mano llegó a Murcia el segundo corregidor, el doctor Pedro Sánchez, que realmente fue el primero que pudo afrontar el cometido para el que había sido nombrado, la pacificación concejil a través de un plan de gobierno municipal que concordara a los bandos (9).

En la reforma que del concejo murciano hizo el corregidor Pedro Sánchez en 1399, entró como punto de arranque la revisión del caso de su antecesor no admitido en 1394, Ruy Méndez de Sotomayor; los esfuerzos en pro de la reafirmación del cargo fueron tanto más tenaces cuanto que las alteraciones sociopoliticas se agravaban, convirtiéndose en un índice medidor de la fuerza renovadora que entrañaba la politica de Enrique III. En cuanto Sotomayor pudo conocer la normalización que en Murcia se estaba produciendo con la violenta y drástica entrada de Dávalos en ella, envió una carta de Enrique III que databa de cinco años atrás (10), en la que se hacía un análisis recordatorio de las condiciones en las que este oficial había sido enviado a Murcia en 1394, como juez y corregidor de la ciudad con un salario diario de 100 maravedís, y las circunstancias en las que se le había impedido la entrada en ella por medio de una partida de peones y caballeros armados que salieron contra él obligándole a permanecer en Molina, hasta que convencido de la inutilidad del intento regresó desde alli a la corte. A través de rey, Sotomayor reclamaba una indemnización por el tiempo que había estado en Murcia más los dos viajes que hizo, hasta Molina Seca primero y desde esta villa a la corte posteriormente, que se cifraba en 12.000 maravedis.

Pero no quedó zanjada la cuestión planteada, con la reclamación eco-

(9) Martinez Carrillo, M. de los Llanos: Revolución urbana y autoridad monárquica en Murcia durante la Baja Edad Media (1395-1420), pág. 99 y 133, Univ. de Murcia, Academia Alfonso X El Sabio 1980.

(10) Villanueva, 14-6-1394. Acts. Cap. 1399, fol. 74 y sig. (4-11-1399), publicada en Bermúdez Aznar, A. Ob. cit. 
nómica, porque en enero de 1400 Sotomayor llegaba a Murcia por segunda vez, respaldado nuevamente por cartas reales y del adelantado mayor Ruy López de Dávalos, reclamando ante el concejo el corregimien. to de la ciudad, pero se encontró con que los regidores, después de haber leído la carta, cuyo texto no se ha transmitido, y en presencia del lugarteniente y hermano del titular, Lope Pérez de Dávalos, se manifestaron a la defensiva dejando en sus manos la aceptación, “...en tal manera que los fueros e privillejos de la çibdat sean guardados, et otrosi en tal manera quel dicho Ruy Mendes non se entrometa mís de quanto Garçy Sanches librava..." (11).

Las vacilaciones e incertidumbres propias de una época de cxperimentación institucional, se acusan en los enfrentamientos verbales y las rivalidades del concejo con Sotomayor y el alcalde impuesto anteriormente a la ciudad junto con el corregiclor Pedro Sánchez, García Sánchez del Castillo. Es posible que el nombramiento de ambos, que se produjo de forma paralela a la entrada de Dávalos en Murcia, concluyese hacia finales de 1399 , o por lo menos así lo entendieron los murcianos, que una vez aceptada la obediencia que la reforma municipal implicaba, se vieron sorprendidos con la nueva llegada de Sotomayor como corregidor. Para ellos un corregidor y un alcalde impuestos ya habian sido suficientes, y no esperaban la continuación puesto que los objetivos inmediatos quedaban cumplidos tras la marcha de Pedro Sánchez.

Debieron de existir tensiones entre las sesiones concejiles del 25 y el 27 de enero, pues Sotomayor se presentó en la segunda quejándose extrañado de que los regidores se hubieran escudado en la mediación del adelantado para pedirle “...que non se entrometiese de librar nin juzgar en este dicho año segund lo juzgaba e avia usado juzgar Garçy Sánchez del Castillo..." (12), y también debió de sentir recelo por la posible eventualidad de una segunda inadmisión; por ello aceptó no ampliar su jurisdicción más allá de las competencias de la alcaldía, comprometiéndose a

(11) Acts. Cap. 1399, fol. 179 rev. (25-1-1400).

(12) Acts. Cap. 1399, fol 181 (27-1-1400). 
“...non usar de corregimiento alguno..." aunque tenía nombramientos reales que se lo permitían, y a no delegar su oficio en persona que no fuera vecina de la ciudad. Sotomayor venía dispuesto a asumir el corregimiento, y cl concejo, al que tres meses antes le habían ajusticiado brutalmente a su principal cabecilla, aún tuvo fuerzas para doblegarlo hasta hacerle conformarse con una oficialía menor, la alcaldía.

A los dos días de esta segunda entrevista, el 29 de enero, propuso como hombre de confianza y consejero a Juan Alonso de Pagán, que ya había sido alcalde en el año 1395-1396 bajo las directrices de Laza, y ante la disconformidad concejil tuvo que hacer una nueva concesión desistiendo del nombramiento, para que fuese el propio concejo quien lo hiciera; de este modo el nombrado fue Bartolomé Ruiz de la Cerda (13) que en aquellos momentos estaba más en la línea concejil.

Resulta sorprendente la fuerza del concejo, que había recibido un golpe tan claro en su autonomía y que sin embargo luchaba por conservarla con una energía sin desmayo: el corregidor Pedro Sánchez había sido el instrumento coyuntural de reforma concejil que el adelantado mayor precisó tras las luchas civiles de la década anterior, y una vez clestabecida la normalidad y puestas las bases de la convivencia con una reforma concejil, que posibilitaba el acceso mecánico de los dos bandos ciudadanos a poder, era suficiente en opinión municipal, con una alcaldía real con poderes judiciales muy reforzados, que en opinión de Sotomayor estuvo desempeñada hasta el 24 de enero por García Sánchez del Castillo, y desde entonces por él mismo. Los hechos se encargaron de mantener a ambos por algún tiempo en una tensa dualidad.

La sustitución de uno por otro distó mucho de ser automática, ya que cuando los nuevos planteamientos fueron conocidos por Ruy López de Dávalos, a través del propio Sotomayor que acudió a entrevistarse con él, el adelantado mayor intentó mantener a ambos pero en las dos dife-

(13) Acts. Cap. 1399, fol. 182 (29-1-1400). 
rentes oficialías, Sotomayor como corregidor y García Sánchez del Castillo como alcalde (14): sus decisiones fueron leídas en el concejo del día 9 de febrero en presencia de su lugarteniente $y$ del propio alcalde, sin que sirvieran para serenar los ánimos y suavizar presiones.

Ruy Méndez de Sotomayor no desistía, presentó por escrito su protesta referente a que no admitía que la alcaldía siguiese en manos de García Sánchez, después de que él ya hubiese jurado el cargo y su rival cesado en él, a pesar de lo cual “...usa del dicho juzgado et me lo turba e embarga, porque yo dello non puedo usar..." (15). El adelantado mayor pretendía mantener ambos oficiales y el concejo, a lo sumo, solo soportaba una, la alcaldía, que por estar subordinada al corregimiento debía recibir un menor salario. En el fondo esta era una de las bases del probema.

La otra era la presión ininterrumpida de Juan Sánchez Manuel, que utilizó la discusión entre los dos oficiales como estímulo para un nuevo intento de movimiento popular con el señuelo de las grandes cantidades monetarias que continuamente sangraban a la ciudad en concepto de impuestos o de salarios de los oficiales reales, que encabezados por el condestable Dávalos en su papel de adelantado mayor del reino murciano, estaban participando en mayor o menor grado, en los intentos de introducción de la reforma del concejo.

En este ambiente, la persona más clestacada fue el alcalde García Sínchez del Castillo, que recibía simultáneamente sobre sí los empujes de Sotomayor destinados a sustituirle y los de los vecinos disconformes con su sometimiento; acusado de robo y cohecho porque estaba vendiendo las incautaciones hechas a los sentenciados como culpables mayores de las luchas civiles recientemente superadas, tuvo que dejar Murcia y refugiarse en Molina; el alcalde se defendió con energla al tiempo que se ofreció voluntariamente a someterse a la justicia ciudadana si se probaban los deli-

(14) 6-2-1400, Acts. Cap. 1399, fol. 201 (19-2-1400), apéndice n." 1.

(15) Act. Cap. 1399, fol 198 rev. (19-2-1400), apéndice n. 2. 
tos de los que se le acusaba. En última instancia todo se reducía a un enfrentamiento entre el poder real que él significaba y el empobrecimiento absoluto de las gentes y la hacienda concejiles, incapaces para arbitrar unos salarios que la crisis demográfica y económica de la ciudad convertían en motivo de nuevos intentos de enfrentamiento urbano.

Bárel afirma que en la ciudad no habia un solo "actor social" que no intentase en uno u otro momento poner la fuerza popular al servicio de su estrategia y califica a la población urbana de "politizada"; utilizando el término con el cuidado necesario, resulta válido para los hechos murcianos, en los que Sánchez del Castillo puso al concejo como testigo de su honradez, negando haber “...sacado muy grand thesoro. et so maravillado en vos otros creer semejantes cosas, ca si yo robé del conçejo, los regidores lo saben et darán fe sy quisieren desir verdat." (16).

Se mantuvo dispuesto a seguir cumpliendo las órdenes reales referentes a la venta de bienes de los sentenciados y gestionar el pago de todas las cantidades debidas, tanto en concepto de salarios como de impuestos (17), y al mismo tiempo exculpaba al "...pueblo inoçente, ca no sabe lo que se façe et nunca dellos reçebi enojo...", por el contrario acusaba a sus dirigentes de ser los instigadores del problema que la reforzada alcaldía estaba causando. Después de reiterar que no lo retenía en Murcia más que el deber contraido de terminar de cobrar las cantidades que la ciudad debía. concluía el escrito, y tal como lo dijo lo cumplió obligado a ello por Juan Sánchez Manuel, a quien desde el día 26 de febrero los documentos citan como procurador general de la ciudad.

(16) Barel, Yves: obra citada, pág. 239. 23-2-1400, Act. Cap. 1399, fol. 204 (26-21400).

(17) Martinez Carrillo, M." de los Llanos: "Setvicios" castellanos y politica municipal. Aspectos fiscales de la reforma concejil murciana de 1399 . Miscelánea Medieval Murciana. vol. V. Departamento de H.a Medieval. Universidad de Murcia 1980. 


\section{Reacción concejil contra las oficialias reales.}

La contundencia tan claramente expuesta por el alcalde real, obligó a Ruy Méndez de Sotomayor a desplazarse por segunda vez en este período a la corte (18), a presentar su punto de vista sobre el gran problema; en ella fue corroborado por Enrique III como juez y corregidor a petición y en sustitución del propio adelantado mayor Dávalos (19), quien con ello intentaba conseguir su principal objetivo político en la ciudad, el sometimiento regular de Murcia a un funcionario regio que garantizase el fortalecimiento de la autoridad real frente a la oligarquía local.

Su regreso a Murcia se produjo en la segunda quincena de marzo compareciendo ante el concejo en la sesión del día 23 con la confirmación real de su nombramiento como corregidor, más otro de igual signo del adelantado mayor, en el que Dávalos repetía inequívocamente la idea de que Sotomayor, su "primo", era nombrado juez de la ciudad "...segunt que mejor e mas complidamente usan en todas las çibdades e villas e lugares en que el Rey mi señor pone sus jueses...". La intervención real ya se consideraba suficientemente generalizada para ser conocida, y añadía que “...mi voluntad es quel dicho Ruy Mendes sea jues en esa dicha çibdat por mi e non otro alguno, e tan complido poder como el dicho Señor Rey me dio a mí por su carta, otro tal e tan compliclo le do yo al dicho Ruy Mendes..." (20).

El desenlace momentáneo de las tensiones tuvo lugar en el concejo general del jueves 25 de marzo, que se celebró en la plaza de Santa María la Mayor; los procuradores murcianos, que a comienzos de diciembre del año anterior habían acudido al llamamiento hecho por el rey para atender a las necesidades bélicas que se presentaban en Portugal, mostraron a los vecinos estos documentos, los últimos referentes al reconocimiento de So-

(18) Act. Cap. 1399, fol. 202 rev. (24-2-1400) y 211 (28-2-1400).

(19) Las Parrillas 9-3-1400, Act. Cap. 1399. fol. 228 rev. (23-3-1400), apéndice n. ${ }^{\circ} 3$.

(20) 10-3-1400, Act. Cap. 1399, fol. 229 (23-3-1400), apéndice n." 4. 
tomayor, quienes una vez conocidos, contestaron como institución concejil que “...le plasia quel dicho Ruy Mencles de Sotomayor oviese el dicho juzgado...", declaración que no tuvo consecuencias prácticas al obtener Juan Sánchez Mautuel de los allí reunidos, el reconocimiento del nombra. miento de procurador general de la ciudad, el mismo que ostentó y costó la vida a Andrés García de Laza unos meses antes, el mismo que él ya habia obtenido en 1391 cuando el proceso cle enfrentamients de bandos cmpezaba a radicalizarse, y una vez admitido por los asistentes, en condiciones económicas idénticas a las que había tenido Laza, anunció claramente, en un gesto, simultáneamente radical y destemplazo, que estaba dispuesto a acudir a la corte si el rey lo llamaba para hacerle “...bien c merçet..." (21). A partir de aqui la reacción concejil se convirtió en puro trámite, incluidas las dudas que pudieran quedar acerca de nuevas sanciones regias, ya que Enrique III confirmaba el perclón general que en su nombre había concedido el adelantado mayor, tras la ejecución de Laza, a todos los participantes en las luchas civiles, e instaba a su cumplimiento en todo el reino (22).

Desde entonces y hasta noviembre de 1401 en que fue expulsado (23), Juan Sánchez Manuel se mantuvo en la procuración general de la ciudad aprovechando la crisis cortesana que colocó a Dávalos circunstancialmente en el ocaso, en su doble papel de condestable de Castilla y adelantado mayor de Murcia y que arrastró consigo a Sotomayor, quien no tenía otras fuerzas adicionales para continuar reivindicando el oficio, del que ya $\mathrm{em}$ pezaba a desistir, pero inmisericorde para no dejar escapar cualquier maravedí que le pudiese pertenecer en concepto de salario.

La correspondencia enviada por Enrique III contestando a las más diversas cuestiones ciudadanas, llegó a Murcia torrencialmente a partir del 25 de marzo, todos los documentos reales con fecha de 6 de marzo en Oro-

(21) Act. Cap. 1399, fol. 233 y sig. (25-3-1400).

(22) Oropesa 6-3-1400, Act. Cap. 1399, fol. 235 (25-3-1400).

(23) Martinez Carrillo, M. de los Llanos: Revolución urbana..., pág. 107 y 152. 
pesa, señal inequivoca de que las relaciones de obediencia respecto a la corte habían cambiado. Garcia Sánchez del Castillo una vez concluida su función de reorganizador de la gran deuda fiscal que la ciudad tenía pendiente, había dejado Murcia, empujado por Juan Sánchez Manuel y sus hombres, y el 15 de abril se leía en el concejo una nueva carta del adelantado mayor presentada por el propio Sotomayor, que es una preciosa y subjetiva recapitulación testimonial de todo el proceso que Murcia había padecido y protagoniza-lo (24), en la que Dávalos pasaba del estupor que le produjo el conocimiento de la nueva oposición ciudadana, “....sabiendo cuanto mal e daño vos vinieron por lo fecho en los tienpos pasados e de derecho deviera venir, salvo sy non fuera por el Rey mi Señor e yo en su nombre, usa de piedat con vosotros...", a la recomendación enérgica de que “...vos pongades en buen regimiento segunt que lo yo ordené quando allí partí e non creades a los que de tales ayunteamintos como los fechos les plase e de los que escíndalo quieren...", para terminar pidiendo que Sotomayor fuese oido en su nombre. Sotomayor ya no habló más que para reclamar sus salarios no cobrados.

\section{Reconocimiento concejil del corregimiento.}

La falta de documentación concejil ordinaria durante un año, descle junio de 1400 hasta la misma fecha de 1401, impide conocer directamente las circunstancias a corto plazo derivadas de la fáctica renuncia de Sotomayor como corregidor, pero posteriormente, discrepancias existentes entre el interesado y el concejo de la ciudad a finales de 1401 , por el salario que debió de percibir, tras el resurgir del potente Dávalos en la Corte, la expulsión de Juan Sánchez Manuel de la ciudad y la entracla en vigor del plan de gobierno concejil organizado por el corregidor Pedro Sánchez, hacen pensar que el nombramiento era por un año y hubiese alcanzado, de haberse cumplido,, los finales del año 1400.

Por entonces reclamaba 36.000 maravedís de 2 blancas de sueldo total,

(24) (10-3-1400), Act. Cap. 1399, fol. 266 (15-4-1400), apéndice n. ${ }^{\circ} 5$. 
que correspondían a cien maravedís diarios durante un año, tal como se le había prometido en el nombramiento que recibió en 1394 y al margen de que los problemas planteados frente al alcalde Sánchez del Castillo, le hubieran permitido o no hacerse cargo integramente del oficio durante todo el año 1400. Pero el concejo ni se asustó ni se conformó, a pesar de que la situación atravesada en los últimos años no fue precisamente cómoda, por el contrario, a su vez envió a Fernún Calvillo a la corte, a exponer a Enrique III a través de él la imposibilidad de hacer frente a tal cantidad, que consideraba exorbitada e injusta, debido a que Sotomayor sólamente había permanecido en Murcia seis meses, los seis primeros de 1400, por los que ya se le habían pagado 6.000 maravedís, porque la ciudad al no necesitar su presencia y por tanto no haber pedido el nombramiento del oficial, no se sentía obligada a pagarle una cantidad mayor: "...et aun desides que aquellos non avía por que auer segund el trabajo que desides que ende ouo, et desides que aún el non gastó en el tienpo que ay estudo los clichos seys mill marauedís..." (25).

Enrique III no aceptó la exposición ciudadana porque rebajaba de hecho el salario-día del corregidor a la tercera parte de lo que se había establecido en 1394, aunque sí transigió con que se le pagase con más lógica “...el salario que le compliere por el tienpo que y estudo de conplir el dicho anno, despues quel dicho Garçi Sanches partio dencle, et pagadle por renta segund el salario quel dicho condestable ordenó et mandó que pagades por aquel anno".

Ruy Méndez de Sotomayor no se dio por vencido ante el dictamen real al nuevo aspecto del problema planteado en Murcia y a su vez recurrió ante Enrique III contra esta carta que debía “...ser obedesçida et non conplida..." por varias razones que enumeró y expuso de la siguiente manera :

(25) Segovia 7-7-1401, incluida en otra de Sevilla, 11-3-1402. Act. Cap. 1401. fol. 147 (23-5-1402). 
1. Con anterioridad a que Fernán Calvillo presentase la reclamación ciudadana en la corte, Enrique III ya había ordenado que Ruy Méndez cobrase en razón al tiempo que efectivamente había sido corregidor de Murcia.

2. Sotomayor afirmó que en Murcia se le recibió en el oficio “...sin ninguna condición, todos en concordia...", ¿se refería al juramento prestado en enero de 1400 ?, y desmentía cualquier tipo de argumento basado en los trastornos que la presencia de un oficial podía ocasionar, mayores a los que trataba de evitar.

3." Añadía, que incluso el concejo le había pedido de parte del rey "...que non partiese desta çibdat et que bos plasia et plugo que fuese vuestro jues...", en una demostración simultánea de armonía y eficacia.

4. Una vez concluido el nombramiento anual, el propio Ruy Méndez manifestó al concejo que estaba dispuesto a marcharse, salvo que en la ciudad se le pidiese expresamente su continuación, como así ocurrió, “...que respondiestes que non deuia partir dende syn mi licençia e mandado et que vos plasia de la su estada et que fuese y jues...".

5. También, concluido el período del año del nombramiento en el que sucedió a García Sánchez del Castillo, el condestable ordenó por carta que "...ouiese jues en esta dicha çibdat mas tienpo...", por lo cual debía de seguir cobrando según las condiciones de 1394; el concejo aceptó y le entregó a cuenta, primero 3.000 maravedís y posteriormente otros 3.000 .

6. Con todo lo anterior, Sotomayor creia demostrar que estuvo como corregidor en Murcia trece meses con pleno consentimiento de la ciudad y del rey, a través del condestable Dávalos ,en una estancia que fue muy necesaria porque “...después que enbiasteis al dicho Garcia Sánches dende $y$, vosotros non touistes la conueuençia quel dicho mi condestable $i$ vos puso, por lo qual dis que ouo a tornar nueuamente a ser vuestro 
jues...". En su opinión las causas de la precipitada marcha de su antecesor estaban claras: la hostilidad urbana hacia él. ¿Qué pudo pasar desde julio de 1400? ¿Hubo algunas alteraciones en torno a Juan Sánchez Manuel que no tuvieran desenlace definitivo hasta noviembre de 1401?

7." La ciudad y su concejo sabfan de sobra desde 1394 que el salario ordenado para un corregidor era de 100 maravedís diarios, ya que la correspondencia recibida de la corte al respecto había sido inequívoca en este sentido.

Enrique III dio por concluido el asunto corroborando a Sotomayor su respuesta dada al concejo, y así ordenaba que se le pagase el tiempo real de permanencia a 100 maravedís diarios, mís las costas efectuadas por culpa concejil al no cobrar en el momento preciso en que dejaba el oficio.

Con la sentencia real todo debía de haber concluido, pero cuál no debía de ser la situación de práctica miseria de la colectividad urbana. cuando el concejo y el frustrado corregidor se avinieron a ponerse de acuerdo, a pesar de que sus respectivas intransigencias habían sido tan largamente mantenidas que llevaron a los vecinos a auténticas situaciones drásticas.

Ruy Méndez de Sotomayor habia presentado al concejo las contestaciones reales pidiendo su cumplimiento, pero el concejo que se encontró con ellas en una difícil salida, presionado por su aguda crisis demográfica y económica, y la ya inevitable obediencia a las órdenes de Enrique III, nombró una comisión de "rogadores" “...porque fablen e traten con el dicho Ruy Mendes que la su bondat sea de faser alguna suelta destos dichos maravedís...". Tres elementos del patriciado local, los fajardistas Antón y Francisco Abellán y el manuelista Gonzalo Rodríguez de la Cerda, presididos por el lugarteniente de adelantado Lope Pérez de Dávalos, consiguieron de Sotomayor la reducción de la cantidad inicial a 14.000 maravedís de dos blancas, con lo que la cuestión quedó definitivamente subsanada. 
La sombra de Dávalos obligando a la concordia de bandos bajo las amenazas de su justicia ya experimentada, posibilitó el acuerdo y la definitiva puesta en marcha del plan de gobierno que Pedro Sánchez introdujo en los finales del año 1399.

Desde el punto de vista concejil, lo inadmisible en los planteamientos no fue el costo del salario día del corregidor, que permaneció inamovible en sus dos etapas, sino la obligación o no de la ciudad de hacer frente a ello, y en caso afirmativo en qué grado debía serlo. Lo accidentado de las dos estancias de Ruy Méndez de Sotomayor en territorio murciano, y las dificultades puestas al ejercicio de la función, fueron las frecuentes en una época en la que oligarquías concejiles y monarquía entraban en colisión en los municipios, siendo lo más difícil del caso, establecer los limites entre la jurisdicción de las oficialías municipales, copadas por miembros de las oligarquías locales y los oficiales reales de nueva introducción, aún contando con la variedad de circunstancias y casos que se dieron en todas las villas y ciudades castellanas.

Concretamente en Murcia, el corregidor Ruy Méndez de Sotomayor fue el primero de una serie de ellos que con intermitencias cronológicas se nombraron durante todo el siglo $\mathrm{XV}$, cacla vez con una mayor frecuencia (26), como instrumentos del poder real que con los Reyes Católicos quedaron prácticamente institucionalizados. Entre 1394 y 1402 los acontecimientos no fueron en realidad más que la consecuencia de la oposición de la oligarquía local apoyada en el sector más arcáico de la nobleza regional, los Manuel, con toda la resistencia de que fueron capaces, a unos oficiales que trataban de controlar su autonomía.

A largo plazo perdieron libertad de movimientos y se dejaron dirigir a cambio de una progresiva patrimonialización en los cargos que les proporcionaban parte de sus beneficios económicos.

(26) Relación publicada por Bermudrz Aznar. A.: Ob. cit. pág. 73 y sig. 


\section{APENDICE N:."1}

1400, II, 6

El Adelantado Mayor Ruy López de. Dávalos, al concejo de Murcia, confirmando el nombramiento de Alcalde a facor de Garcia Sánchez del Castillo.

Act. Cap. 1399, fol. 201 (19-2-1400)

Al Conçejo, caballeros et escuderos, ofiçiales e omes buenos de la muy noble çibdat de Murçia, yo Ruy Lopes de Davalos, camarero de mi señor el Rey, et su adelantado mayor del Regno de Murçia, vos enbio mucho saludar, como aquellos por quien de grado faria las cosas que a vuestras onrras fuese.

Bien sabedes en como vos enbic una mi carta por la qual vos enbio desir que era merçed del Rey mi señor que Ruy Mendes de Soto Mayor fuese jues e corregidor en esta dicha çibdat et que vos rogava que lo reçibades en el ofiçio del dicho corregimiento por quanto entendia que era pertenesçiente para ello.

Et agora sabed que como quier que vos yo enbie la dicha mi carta, que mi voluntad non fue nin es de tirar luego de presente del ofiçio del alcaldia a Garçia Sanches del Castillo, mas que estudiese et fuese alcalle en esa dicha çibdat, segund lo yo avia dexado fasta tienpo çierto, por que vos ruego que ayades et resçibades por alcalde en esa dicha çibdat al dicho Garçia Sanches segund que lo yo dexe et usedes con el en el dicho ofiçio, segund que fasta aqui avedes usado. Et fasedle recodir con los derechos que ha de aver por rason del dicho ofiçio, en lo qual me fariades grant plaser et devos Dios su graçia. Fecha, seys dias de febrero, año del nasçimiento del nuestro salvador Jhesuchristo de mill e quatroçientos años. Ruy Lopes. 


\section{APENDICE N.. 2}

1400, II, 19

Ruy Méndez de Sotomayor al Concejo de Murcia exponiendo sus derechos al juzgado de la ciudad, que ostentaba el alcalde García Sánchez del Castillo.

Act. Cap. 1399, fol. 198, rev. (19-2-1400)

Señores cavalleros, escuderos e omes buenos, ofiçiales del Conçejo de la noble çibdat de Murçia, yo Ruy Mendes de Sotomayor, vasallo del Rey puesto ante vos, et vos que bien sabedes en como yo paresçy ante vos en los dias pasados, et vos presenté una carta de Ruy Lopes de Davalos, camarero del dicho señor Rey et su adelantado mayor en el Regno de Murçia, en que manda por el poder que el dicho Señor Rey tenia que me resçibiesedes por jues del dicho señor Rey en esta dicha çibdat para juzgar et deterrninar los pleitos segund que Garçi Sanches del Castillo lo abia juzgado e librado fasta aquí, et por quanto el dicho Garci Sanches en vuestra presençia fixo e otorgo quel tiempo avia a juzgar los dichos pleitos et juzgado que era pasado e conplido por lo qual vos, dichos señores resçibiestes a mi el dicho Ruy Mendes por jues en el dicho juzgado y me reçibiestes juramento sobre ello dela guisa que entendiades que cumplia para que usase del dicho ofiçio, et agora por quanto me an dicho y dado a entender quel dicho Garçy Sanches usa del dicho juzgado et me lo turba e embarga, porque yo dello non puedo usar, esto es deserviçio del dicho Rey et del dicho Ruy Lopes y escandalo de la dicha çibdat.

Por esta raçon yo el dicho Ruy Mendes pido e requiero et afronto a vos los dichos señores que porque esta dicha çibdat este muy bien sosegada para serviçio del dicho señor Rey, pues a mi reçibiestes por su jues en esta dicha çibdat, que non consintades al dicho Garcia Sanchez que me turbe y enbargue el dicho juzgado por que yo pueda usar, librar e desenbargadamente del dicho juzgado, para que servicio y mandado del dicho Señor Rey et del dicho Ruy Lopes en su lugar sea conplido et la dicha 
çibdat este asosegada por serviçio del dicho Señor Rey, protestando que si asi faser e conplir non lo quisieredes, et por esta rason algund daño e menoscabo viniere a la dicha çibdat y a los vesinos e moradores della y a mi el dicho Ruy Mendes por ello, perjudiçio algund non faga pues por mi non queda nin quedara de asosegar la dicha çibdat et de conplir serviçio y mandado del dicho Señor Rey, et el dicho Ruy Lopes en su lugar el dicho Señor Rey lo pueda demandar et açalapujar a vosotros, que le consintades, o a quien la su merçed fuese y no a mi, et porque non podades desir nin poner que esto que dicho es requerido y afrontado, non vos sea, pido a Pero Roys Delgadiello, vuestro escribano, que me de dello testimonio para guarda y salvaçion del mi derecho.

\section{APENDICE N. ${ }^{\circ} 3$}

1400, III, 9, Las Parrillas.

Enrique III al concejo de Murcia, confirmando el nombramien. to de corregidor de Ruy Méndez de Sotomayor, hecho por el Adelantado Mayor Ruy López de Dávalos.

Act. Cap. 1399, fol. 228, rev. (23-3-1400)

Don Enrique por la graçia de Dios, Rey de Castiella, de Leon, de Toledo, de Gallisia, de Sevilla, de Cordova, de Murcia, de Jahen, del Algarbe, de Algesiras e señor de Viscaya e de Molina al Conçejo, cavalleros, escuderos, regidores, ofiçiales e omes buenos de la noble çibdat de Murçia, salud e graçia.

Bien sabedes que yo ove enbiado a esa çibdat a Ruy Lopes de Davalos, mi camarero e mi adelantado mayor dese regno de Murçia et fue ayn, agora es ini merçed, que el que fuese mi jues e corregidor en esa dicha çibdat e agora el dicho Ruy Lopes dixo ne quel que enbiaba alla en su nonbre para que oviese por el dicho judgado (a) Ruy Mendes de Soto Mayor, porque vos mando que usades el poder del dicho Ruy Lopes diere e 
ha dado al dicho Ruy Mendes sobre rason del dicho judgado et usedes con el e con los que el por si pusiere en el dicho ofiçio, asy en lo çevil como en lo cremynal bien e conplidamente, segunt que mejor e mas conplidamente usastes con los otros que han seydo jueses en esa dicha çibdat o segunt se usa con los otros jueses de las otras çibdades de mis regnos, e le recudades e fagades recudir con el salario e derechos que al dicho ofiçio pertenesçen e pertenesçer deven en guisa que les non mengue ende alguna cosa.

Et los unos e los otros non fagades ende al por alguna manera, so pena de la mi merçet e de los querpos e de quanto avedes e de mas e por qualquier o qualesquier de vos por quien fincar de lo asi faser e conplir mando al ome que vos esta mi carta mostrare, que vos emplase que parescades ante mi personalmente del dia que vos emplace a quinse dias primeros siguientes, so la dicha pena a cada uno a desir por qual rason non conplides mi mandado. Et mando so la dicha pena a qualquier escrivano publico el qual por esto fuere llamado, que dende ende al que vos la mostrare, testimonio signado con su signo, porque yo sepa en como conplides mi mandado.

Dada en Las Pariellas, nueve dias de março, año del nasçimiento del nuestro Salvador Jhesuchristo de mill e quatroçientos años. Yo Ferran Alonso la fis escrivir por mandado de Nuestro Seyor el Rey. Yo el Rey.

\section{APENDICE N." 4}

1400, III, 10

Carta de Ruy López de Dávalos al Concejo de Murcia, confirmando a Ruy Méndez de Sotomayor como Corregidor.

Act. Cap. 1399, fol. 229 (23-3-1400)

Conçejo, cavalleros, ofiçiales e omes buenos de la muy noble çibdat 
de Murçia, yo Ruy Lopes de Dávalos, camarero de nuestro Señor el Rey e su adelantado mayor del regno de Murçia, vos enbio mucho saludar como aquellos por quien de grado faria las cosas que a vuestras honrras fuesen; fago vos saber quel Rey mi señor enbia a esta çibdat sobre algunas cosas que cunplen a su serviçio a Ruy Mendes de Soto Mayor, mi primo, por que vos digo de parte del dicho Señor Rey por el poder que del tengo e ruego de la mia, que oyades e resçibades por jues en esa dicha çibdat por mi al dicho Ruy Mendes, e usedes con el e con los que el por si pusiere en el ofiçio del judgado, scgunt que mejor e mas conplidamente usan en todas las çibdades e villas e lugares en que el Rey mi señor pone sus jueses e le recudades e fagades recudir con todos los derechos e salarios que al dicho ofiçio pertenesçen e pertenesçer deven en qualqier manera, bien e conplidamente en guisa que le non mengue ende alguna cosa, ca yo le do poder conplido segunt que yo lo he del dicho Señor Rey e non lo dexedes de faser e conplir, $[e]$ non enbargart qualesquier carta o cartas que yo aya dado a qualesquier personas que mi merçed e voluntad es del Rey mi Señor, e mi voluntad quel dicho Ruy Mendes sea jues en esa dicha çibdat por mi e non otro alguno, e tan conplido poder como el dicho Señor Rey me dio a mi por su carta, otro tal e tan conplido le do yo al dicho Ruy Mendes, por que pueda usar del judgado en esa dicha çibdat, et non fagades ende al so pena de la merced del Rey mi señor e de dies mill maravedis para la camara, et desto le mande dar esta mi carta firmada de mi nombre e sellada con mi sello.

Fecha dies dias de março, año del nasçimiento del nuestro Salvador Jhesuchristo de mill e quatroçientos años. Ruy Lopez.

\section{APENDICE N. ${ }^{\circ} 5$}

1400, III, 10

El Adelantado Mayor Ruy López de Dávalos al concejo de Murcia, haciendo un llamamiento a la convivencia y anunciando la 
llegada del corregidor Ruy Méndez de Sotomayor. Act. Cap. 1399, fol. 266 (15-4-1400).

Conçejo e alcalles e alguasil e ofiçiales e omes buenos de la muy noble çibdat de Murçia, yo Ruy Lopes de Davalos, camarero de mi señor el Rey e su adelantado mayor del Regno de Murçia vos enbio mucho saludar como aquellos para quien honrra e buena ventura querria.

Bien sabedes en como enviaste por vuestros mandaderos al dicho señor Rey a Juan Sanchez de Ayala e a Remir Sanches de Madrit, a los quales el libró bien e graçiosamente todas aquellas cosas que por vuestras petiçiones demandastes e estando para partir los sobredichos llego Ruy Mendes de Sotomayor, mi pariente, el qual me conto largamente del movimiento que agora fue fecho en esa çibdat, de lo qual yo so mucho maravillado de vos otros mover a faser tal cosa, sabiendo quanto mal e daño vos vinieron por lo fecho en los tienpos pasados e de derecho deviera venir, salvo sy non fuera por el Rey mi Señor e yo en su nonbre, usa de piedat con vosotros e por la mejor via e mas provechosa a vos otros se puso en pas e sosyego esta dicha çibdat.

Otrosy bien sabedes en como yo por el poder que el dicho Señor Rey levava non parando mientes a ningunos yerros que algunos de vosotros teniades fechos, vos fise perdon general e vos otorgue $e$ di otras graçias e perdones e puse regimientos quales cunplian a onrra desa çibdat e a pas de vosotros. E allende desto sabedes bien que despues que yo al Rey mi Señor llegue, le fise relaçion desa çibdat e del logar en que estava e como era su serviçio que vosotros fueredes guardados e renobados e vos diese manera con syn daño de vuestras fasiendas, pagar lo que deviades e mas que fuese su merçed de vos otorgar algunas cosas, que en las vuestras petiçiones le enbiariades declarar por lo qual el por su merçed a mi petiçion, vos libró todo aquello que por vosotros fue demandado e contenido en las dichas petiçiones por lo qual vosotros aviendo temor de Dios e del Rey mi Señor, podedes bien bevir en pas et 
sosyego, et agora paresçeme que non parando vos mientes a todas las cosas que yo por vosotros fise en tanto que allá estude, e despues que aca vine, vos libré con el Rey mi señor, dadesme agora este galardón, levantar vos alas de comun e non querer justiçia nin sosyego, antes buscando manera por do lo vuestro sea en condiçion e yo syenpre tove, que otro galardon oviera yo desa çibdat a lo menos quel Rey mi Señor creyera lo que de vosotros le avia dicho, e quando lo que yo por vosotros fise estando allá e despues que aca vine vos libré, non paradades mientes, deviades pensar qué ay Rey en Castiella e Señor que ama Justiçia a caso que vosotros uso de piedat e es de fuerça que de estas cosas asy continuaredes que el aya sentymiento dello e remedio como a su serviçio cumpla, por quel amando bien e onra e provecho desa çibdat e de todos vosotros, vos ruego e pido de mesura, que paredes mientes a las dichas merçedes quel dicho Señor Rey vos ha fecho e vos yo procure, e como ya tenedes logar e manera de lo bien pagar, e de lo fecho non curcdes, antes obedesçiendo las cartas e mandando del dicho Señor Rey, e la su justiçia, vos pongades en buen regimiento segunt que lo yo ordené quando de ella party e non creades a los que de tales ayuntamientos como los fechos les plase e de los que escandalo quieren, ca lo non fasen so otra entençion salvo de poner vos en condiçion los cuerpos e quanto avedes e a mi en carga con el Rey por vos sostener e mantener vuestra vos, e do esto quisyeredes faser el dicho Señor Rey acresçentar vos ha muchas mas merçedes e mantener vos ha en justiçia, en manera que cada uno sea señor de lo suyo, e do al quisyeredes, seed çiertos que de ninguna cosa de lo librado non gosaredes nin del dicho perdon que yo en su nombre vos fise et allende desto el remediara de manera que vos podredes arrepentir en tiempo que vos non haprovechara.

Et por ende vos requiero con Dios que todos vos llegades al sosyego e a la mejor parte e vos unierades con el adelantado Lope Peres mi hermano e con la justiçia del dicho Señor Rey, porque el con vosotros e con la dicha justiçia se ponga tal escarmiento e se faga justiçia en los que es- 
candalo quieren, por que los que syn culpa sodes non padescades aires de comun, e sobre todas estas cosas el dicho Ruy Mendes va alla el qual fablara con vosotros algunas cosas de mi parte, ruego vos que le creades de todo lo que de mi parte vos dysiere, et devos Dios su graçia. Fecha dies dias de março. Ruy Lopes. 